\title{
A CASE OF ACUTE MIDDLE-EAR SUPPURATION AND MASTOIDITIS WITH SOME UNUSUAL SYMPTOMS.
}

\author{
By J. S. Fraser, M.B., F.R.C.S.Ed., \\ Assistant Surgeon Ear and Throat Department, Royal Infirmary, Edinburgh ; \\ Lecturer on Diseases of the Nose, Throat and Ear, Surgeons' \\ Hall, Edinburgh.
}

THe patient was a medical graduate, aged thirty, of somewhat neurotic temperament; some years previously he had suffered from septicæmia, and, though the pulse was slow and regular, a pre-systolic mitral murmur could be heard on auscultation. For some months before the present illness the patient had been in bad health, and greatly troubled by dyspepsia. He had been engaged in the study of oto-laryngology for the last two years. In August of this year the inferior turbinals were cauterised, as the patient complained of remittent nasal obstruction, due to vascular engorgement.

On September 12, whilst bathing in the public salt-water baths he got some water into his nose and mouth during a long dive. On blowing his nose he felt some of the fluid pass into his right ear. There was no pain during the rest of this day nor at night, but on the 13th there was slight discomfort in the daytime and at night marked otalgia. Next day the pain increased, and the tympanic membrane was seen to be red and to have lost its polish; that night the temperature rose to $101.8^{\circ} \mathrm{F}$., and in spite of cocaine and carbolic glycerine drops the patient had a bad night; there was no mastoid tenderness at this time. On September 15 there was a bluish bleb on the posterior wall of the bony meatus; mastoid tenderness was present, especially on pressure, at the tip and over the antrum; the patient left work and went to bed. The pain in the ear continued, and at night, in spite of morphia, he only slept for two hours.

September 16.- Severe throbbing pain in right ear, tympanic membrane seen to be bulging; patient admitted to hospital. Paracentesis of right tympanic membrane, under local anrsthesia by Dr. Logan Turner; morphia (gr. $\left.\frac{1}{3}\right)$ hypodermically. Temperature $100 \cdot 6^{\circ} \mathrm{F}$. on admission.

September 17.-Patient much better, no pain ; profuse discharge from right ear of serum slightly tinged with blood; mastoid tenderness practically disappeared. Aural syringing every two hours. 
September 18.-Otalgia returned; mastoid tenderness over tip and antrum. Veronal (gr. $\mathrm{xv}$ ) at night; slept four hours.

September 19.-Severe throbbing pain all over right side of head and face; discharge slightly more purulent; marked mastoid tenderness. After carefully syringing and drying the meatus cover-glass films were made from the pus obtained from the perforation by means of a sterile platinum loop. Report: Films show numerous ovoid and round Gram-positive cocci in pairs, and less frequently in short chains; no other bacteria. Stroke cultures on Loeffler's serum (made after again sterilising the needle) yielded a pure growth of Streptococcus brevis. Temperature at 8 p.m., $100 \cdot 4^{\circ} \mathrm{F}$.

September 20.- Patient reported a bad night: pain and tenderness increased. In the absence of Dr. Logan Turner the writer performed the operation at $3.30 \mathrm{p} . \mathrm{m}$.; chloroform. Incision in retro-auricular groove. Mastoid cortex appeared more red than normal, and on using the gouge there was considerable bleeding from the congested bone; the cortex consisted of small pneumatic cells and diploë. Pus was not reached till the antrum was opened, when a drop or two escaped under slight pressure; the antrum was small and deep. (Bacteriology: pure culture of Streptococcus pyogenes.) The mastoid cortex and external wall of the antrum were freely removed, but as the cells exposed contained no pus and were merely congested the tip was not removed. A free incision was made in the tympanic membrane through an aural speculum, but there was no escape of pus. The large bony cavity was cleaned out with peroxide solution and lightly packed with iodoform worsted. The patient had a fairly good night after the operation.

September 21.-Patient complained of a good deal of pain; external dressings changed; temperature $100^{\circ} \mathrm{F}$. at 8 p.m.

September 22.-Wound dressed; meatal packing removed almost dry; little reaction about bony cavity.

September 23.-Pain continues. Blood-count gives following result: white cells 9700 ; polymorphs 78 per cent.; large mononuclear 20 per cent.; small mononuclear 2 per cent. Iodine reaction negative. Temperature $99 \cdot 6^{\circ}$ F. at 8 p.m.

September 24.-Ten c.c. of anti-streptococcus serum injected into cellular tissue of right lumbar region. Wound dressed; granulations beginning to form; slight formation of pus; some tenderness on pressure over posterior border of mastoid.

September 25-30.-Pain in right ear continues severe-worse 


\section{The Journal of Laryngology, [January, 1909.}

at night: pain shoots up to vertex and also over distribution of fifth right cranial nerve. Wound dressed daily; meatal packing dry ; fairly copious purulent discharge from mastoid cavity; pus oozes out of aditus when patient performs Valsalva's experiment. Tenderness on pressure at mastoid tip and over posterior border, but no pain on tapping the bone exposed in posterior wall or floor of the cavity.

October 1-4.-Edema noticed over posterior edge of mastoid wound ; during next three days this continued and spread up over temporal and parietal region on the right side almost to the vertex.

October 5.-Urticarial eruption appeared, especially marked on flexor aspects; the rash was raised, papular, with a somewhat flattened top, and there was marked redness around; the rash was very irritable and came out in patches and disappeared again very quickly; œdema over mastoid continues; the wound cavity shows copious granulation tissue formation. Blood-count: White cells 7100 ; polymorphs 73 per cent. ; iodine reaction negative. Temperature $100 \cdot 2^{\circ} \mathrm{F}$. at 8 p.m.

October 6-7.-Patient has less pain during the day and sleeps somewhat better at night; wound dressed daily. No pus now exudes from aditus on Valsalva's experiment, but patient feels air enter the tympanic cavity ; mastoid œdema disappearing.

October 8.-At 3 p.m. the upper lip suddenly swelled up, and this condition lasted till the following morning.

October 9.-Granulations in wound cavity tend to unite in spite of packing; tympanic membrane healed, but still red and thickened; malleus not visible. Whispered speech heard by right ear at six inches, ordinary voice at two yards. Edema over mastoid greatly diminished; tip and zygoma now free. Tenderness on pressure also considerably less. Blood-count: White cells 5700; polymorphs 77 per cent.

October 12.-Whisper right ear at two yards. Mastoid œdema entirely disappeared; temperature normal; still slight tenderness at tip of mastoid and along posterior border.

October 14.-Local anæsthesia with patient in recumbent position; cocaine ( $m l x$ of $\frac{1}{2}$ per cent. solution, with $m v$ of adrenalin chloride 1 in 1000) injected under edges of the wound. Immediately afterwards, and before any incision had been made, the patient hecame very pale, vomited, and complained of severe cardiac pain ; the pulse was rapid and feeble; great dyspncea was present, and the patient broke out into a "cold" perspiration. This condition lasted for ten minutes in spite of sal volatilë, fresh air, etc. When 


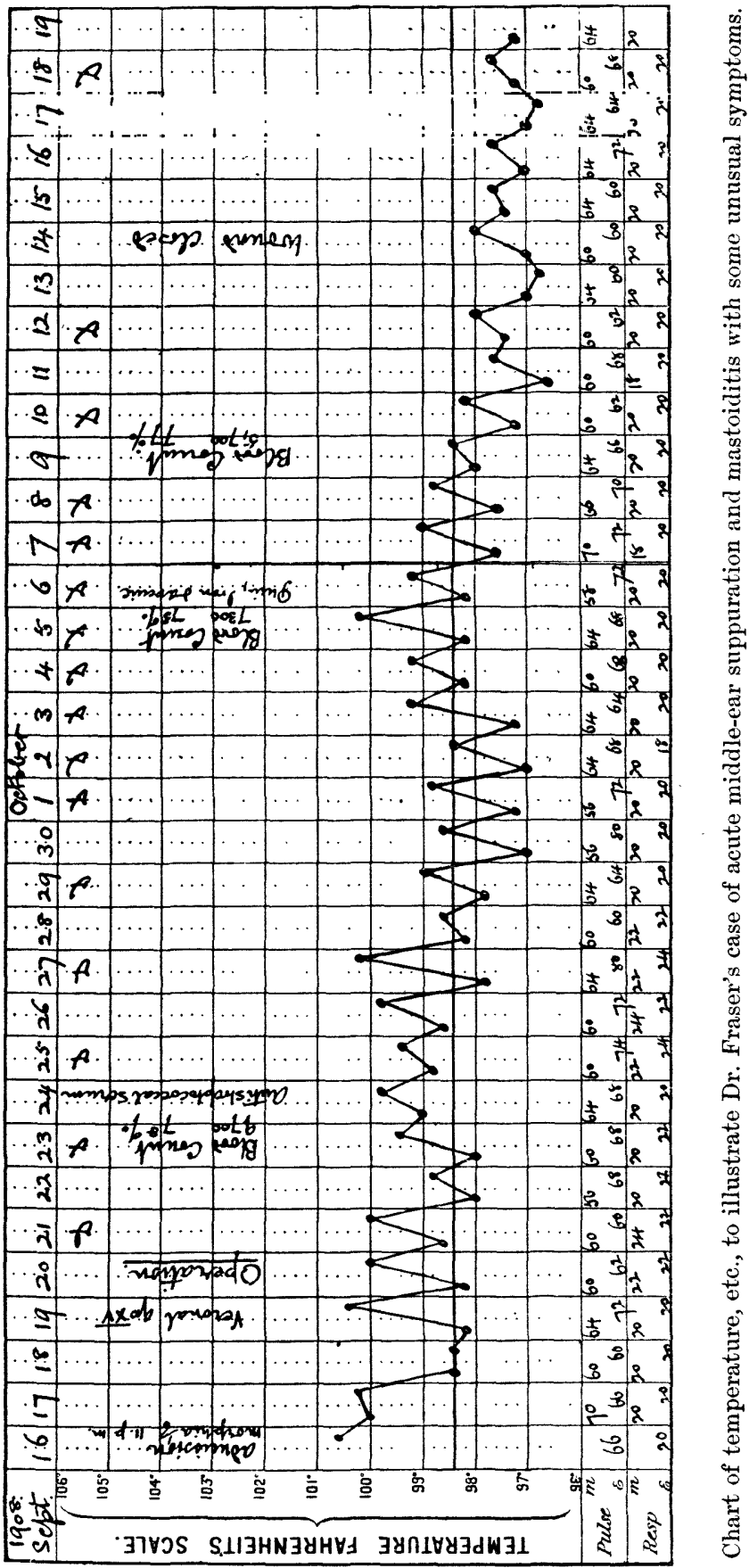


patient had recovered the edges of the wound were undermined, freshened, and united.

Thereafter there was nothing of importance to note; within five days the wonnd had firmly healed, leaving only a linear scar ; the hearing had returned almost to normal, and by the end of October had become quite normal.

\section{REMARKS.}

The case presents several points of interest-the previous history of septicæmia and heart trouble, the neurotic condition, and the knowledge of otology. The origin of the otitis media was, of course, a not uncommon one. As regards the bacteriology it is evident that the same organism appeared as diplococci as short chains and, in the cultures from the antral pus, in the longer chains characteristic of Streptococcus pyogenes. At the operation it was somewhat surprising not to find more evidence of bone disease-in fact, at the end of the operation I was by no means sure that I had been justified in carrying out the Schwartze procedure. No great improvement followed the drainage of the posterior end of the middle-ear cleft and the second free paracentesis, for the pain continued and the temperature remained elevated. It should be mentioned that the patient has, as a rule, a subnormal temperature and a slow pulse, as will be seen from the chart from October 11 to 19 . The patient was troubled by dyspepsia and constipation during the first three weeks of his illness. The most interesting feature in the case was the persistence of mastoid tenderness after the operation and the onset of odema on October 1. I do not think that this had any connection with the injection of anti-streptococcus serum, as an interval of a week elapsed between the two events. The injection was not repeated as it appeared to be of no benefit. The area of œedema followed very closely that of the distribution of the small occipital nerve, and, taken in conjunction with the urticarial rash which appeared on October 5 and the swelling of the upper lip on October 9 , I think that the adema of the mastoid and parietal region cannot be looked upon as a sign of phlebitis of the small veins of the mastoid or of sinus involvement. The tenderness was not increased by deep pressure over the region involved. Further, the bone exposed in the posterior wall of the mastoid cavity was normal in appearance and not tender on tapping. The granulations which sprang up were healthy in appearance. The early cessation of otorrhoea and 
improvement in the hearing were also against any serious complication. It is quite possible that streptococcic infection of the edges of the wound in the soft tissues may have been the cause of the cedema, but, if so, one would have expected this oedema to occur at a shorter interval than ten days after the operation and to have affected the anterior as well as the posterior and lower edges of the wound; further, this explanation does not account for the urticarial rash and the odema of the upper lip. Finally, the blood-count was not in favour of any continuation of the inflammatory process; this showed a moderate degree of leucocytosis two days after the operation, and the percentage of polymorphs was not above what one would expect; the further examination on October 5 and 9 were confirmatory of the improvement in the patient's condition. Had it not been for the valuable aid given by this method of examination together with the knowledge of the previous history and general condition of the patient a further operation would almost certainly have been performed in the beginning of October. The reaction of the patient to such a small dose of cocaine (about gr. $\frac{1}{4}$ ) and adrenalin may of course have been due to idiosyncrasy, but I think that the neurotic element was not altogether absent here.

I am indebted to Dr. Logan Turner for his advice and help on many occasions as well as for permission to record the case, to Dr. John Darling for his kindness in making the blood examinations, and to Dr. W. 'T'. Ritchie for the bacteriological reports.

\section{A CAP FOR DRESSING MASTOID CASES.}

By J. S. Fraser, M.B., F.R.C.S.Ed., Assistant Surgeon Ear and Throat Department, Royal Infirmary, Edinburgh.

More than two years ago I came to the conclusion that the ordinary method of dressing a case after the radical mastoid operation left much to be desired. The gauze strips used in packing the cavity trailed over the patient's neck and auricle before being inserted into their proper position; further, it was impossible to steady or manipulate the patient's head without infecting the left hand of the aural surgeon. To obviate these difficulties I devised the ear-cap shown in the illustration. This cap is merely a loose linen cap-something like a baker's cap-with the addition of a strip of material on one side in which a hole is cut sufficiently large 